\title{
A Comprehensive Approach to Understanding Substance Use Disorder and Recovery: Former Patients' Experiences and Reflections on the Recovery Process Four Years After Discharge from SUD Treatment
}

\author{
Turid Wangensteen $(\mathbb{D} \cdot$ Jacob Hystad
}

Received: 8 April 2021/Accepted: 12 August 2021/Published online: 27 August 2021

(C) The Author(s), under exclusive licence to Springer Nature India Private Limited 2021

\begin{abstract}
This article concerns people who have developed a substance use disorder (SUD) and sought treatment. SUD is understood as a biopsychosocial disorder. People who want to stop using substances or wish to increase their wellbeing while using substances need to undergo a recovery process. We conducted qualitative interviews with 11 former patients four years after discharge from inpatient SUD treatment in the Tyrili Foundation to explore their experiences and reflections on SUD and the recovery process. The findings indicated that recovery processes are complex, and feelings of wellbeing and success vary over time. Several interrelated aspects of life were essential for seeking a better life: Understanding own substance use; Feeling safe; Understanding the impact of close relationships; and Perceptions of participation and belonging. The informants emphasised the need for access to professional and social support during the recovery process, which, for some, will last for many years. Receiving such support is not understood as a defeat, and each person's resources and vulnerabilities should be recognized and acknowledged. SUD and recovery should be understood using the same coherent approach-as an interplay between biological and
\end{abstract}

T. Wangensteen $(\bowtie) \cdot J$. Hystad

Tyrili Foundation, R\&D, Lokkegata 11,

2615 Lillehammer, Norway

e-mail: tuwa@tyrili.no psychological factors and social, political and cultural contexts.

Keywords SUD - Substance use - Recovery · Biopsychosocial approach $\cdot$ Stigma

\section{Introduction}

Substances such as alcohol and legal or illegal drugs have been used for recreation, celebration, and coping with difficult life situations and health problems [37]. Several theories and models have been developed to understand the concept of substance use disorder (SUD), focusing on, for example, self-medication, behaviour, self-regulation, neurobiology or social living conditions [25, 33, 47]. The World Health Organization (WHO) and Norwegian health authority use a comprehensive, multi-disciplinary understanding of SUD based on a biopsychosocial approach. This approach assumes that psychological and biological factors are in constant interplay with relational, social, economic, cultural and political elements in the development and maintenance of SUD and that each person's pathway to developing SUD is unique [10, 11, 37]. Using substances to cope, feel better, and belong may reduce anxiety, restlessness, disturbing emotions, and feelings of hopelessness and loneliness [14, 19]. However, frequent use of 
substances may lead to an addiction. The substances affect the brain's central functions, including dopamine production and executive functions, with a consequent craving for substances and impaired impulse control [47, 49]. This may involve reckless behaviour that is often incomprehensible to other people and may lead to stigma and shame $[16,18,48]$. Mental health problems, such as anxiety and depression, may increase [29], and it may be difficult to maintain social relationships, everyday parenting responsibilities and work routines [18, 34]. The hard work of obtaining, paying for, and using substances becomes all-consuming [37, 47]. Most people who develop SUD either manage their substance-induced life problems adequately or are able to quit on their own or with help from family and friends [42]. For a smaller group of people, substances have too many negative consequences, and they need help and treatment from professionals. In Norway, such treatment is provided in both local-community and specialised healthcare facilities, including short-term and long-term inpatient and outpatient treatment. Understanding SUD is crucial because it affects legal regulations, support and treatment services, and the attitudes of both service providers and the public regarding people with SUD.

The search for a better life is often called recovery. The recovery concepts have underpinned a long history of measuring treatment outcomes for mental health issues and substance use problems. The most common model is the clinical recovery model, which aims to minimise core symptoms, such as the problematic use of substances or mental health issues [6]. A personal and social approach understands the process of being in recovery as an ongoing, non-linear process. Essential is the person's perceptions and descriptions of their current situation regarding wellbeing, belonging to a community, and a positive sense of identity, including perceptions of a better life while living with core symptoms [44]. This entails a change of focus from 'cure' to 'coping' [6, 21, 22, 26, 38]. The person's perceptions of the recovery process and their wellbeing constantly interplay with the relational, social, cultural and political surroundings as understood within a biopsychosocial approach [7, 9, 31, 41, 43].

To our knowledge, few qualitative studies have drawn attention to the complexity that characterises understandings of SUD and the recovery process using a comprehensive approach $[6,7,44]$. Through qualitative interviews, this study explores people's experiences with and reflections on the recovery process after discharge from inpatient SUD treatment with the aim of gaining broader knowledge about the personal and social journey of recovery. The main research question was: How do former patients in SUD treatment describe and understand their personal recovery process?

\section{Methods}

This study was a qualitative sub-study of the Tyrili cohort 2016 study. The Tyrili Foundation is a nongovernmental organisation that runs eight SUD treatment centres in Norway. Norwegian health authorities refer to and pay for the treatment. In the Tyrili cohort 2016 study, quantitative methods were used to examine quality of life, cognitive functioning, psychological distress and experiences of trauma among 138 patients [5, 40]. Most of these patients consented to participate in further sub-studies.

This article presents a qualitative study based on the paradigm of the social construction of the philosophy of science, understanding people's meaning-making as a personal process which is negotiated with other people and provided by culture $[3,13,24]$. Twentyfive informants were chosen to participate in the study. They had completed all the surveys and tests in the Tyrili cohort 2016, which will give us the opportunity to compare results from both quantitative and qualitative data in future. The informant group represented the average age of the patients, and were between 25 and 45 years old, and included both men and women. Fifteen of the 25 former patients responded to our application to participate in the study. Four were positive to be interviewed, but due to private situations (new-born child, substance use) they were not able to keep their appointments. The empirical data consist of in-depth interviews from 11 informants. The number of informants was not determined in advance, and we had the option of continuing the recruitment process and including informants even if some data from the main study were lacking. However, during the 11 interviews, the immediate transcriptions, and the ongoing thematic analysis, we obtained 110 pages (55,000 words) of data material. We considered that to be sufficient to answer the research question about 
how the informants perceived and reflected on the recovery process after they were discharged from inpatient treatment; hence data saturation had been achieved [20, 24]. The informants were recruited by telephone, messenger or mail by one of the researchers.

\section{The Informants}

The informants were six women and five men aged 30-45 years. They all had histories of severe substance use problems over many years. Most of them started using substances at age 12-15, and heroin or amphetamines were their main substances, combined with cannabis, prescription drugs and alcohol.

\section{Interviews}

We chose an interview-based method of data collection, because 'Interviewing is therefore a good way to locate clues to people's personal and cultural meanings that would be difficult to find in any other way' [24], p. 6). Both authors conducted the first three interviews to coordinate and adjust the interview guide. The second author conducted seven interviews solely, and the first author one. The interviews took place in the informants' homes, at their places of work, or in cafés during the summer and autumn of 2020. Four of the interviews were conducted by telephone due to the coronavirus pandemic. Each interview lasted for between one and one and a half hours. The interviews were recorded and transcribed by the authors. We used an interview guide that started with an open-ended question: 'Please tell us about your life since you were discharged from inpatient treatment in Tyrili'. We followed up with more specific questions about substance use, criminality, mental health, physical health, family and social networks, occupations and activities, housing, financial issues and treatment and social services. The interviews were conversational, and the researchers and informants reflected together.

\section{Analysis}

We used a hermeneutic, thematic, analytical approach to look for experiences and meanings in the informants' speech. Looking for informants' meanings included seeking both explicit utterances and less explicit expressions that required interpretation by the researchers [24, 36]. The first step involved both researchers reading and rereading the transcribed interviews. We compiled a set of sub-questions to expand upon the research question: Did they have incidents or periods of substance use, and how did they talk about it? How was their living situation? How was the financial situation? How did they talk about family and friends, connectedness and loneliness? Did they have experiences with education or work-life after discharge, and how did they talk about it? What were their experiences of professional support and treatment? During the process of new readings, we looked for both repeating and unique experiences and ideas in the informants' stories. We used the NVivo11 software, which is designed for coding and analysing qualitative data to systemise the data and select excerpts that shed light on each of the sub-questions. The second step involved interpreting the informants' narratives to understand their perceptions and reflections. Through this process, some main themes in the informants' narratives about their recovery processes emerged. These are presented in the sections regarding Understanding own substance use; Feeling safe; Understanding the impact of close relationships; Perceptions of participation and belonging; and Recognise one's needs for support and treatment.

\section{Ethical Considerations}

Ethical issues were considered during the recruitment, the interviews, the analysis, and the data interpretation. Conducting in-depth interviews about sensitive subjects requires great awareness and respect for the 'informants' emotions and boundaries [12]. Therefore, some potentially relevant follow-up questions were omitted. The informants were encouraged to contact their therapist, family, or friends if they needed anyone to talk to about stressful thoughts and emotions following the interviews. The following quotations were translated by the authors and anonymised, but retain the content and meaning of the original narratives. The informants provided written informed consent before the interviews, they were informed about the right to withdraw and data privacy. The Norwegian Centre for Research Data approved the qualitative sub-study (reference number 800600). 


\section{Findings}

Five main themes emerged through thorough analysis and interpretation of the data: Understanding own substance use; Feeling safe; Understanding the impact of close relationships; Perceptions of participation and belonging; and Recognise one's needs for support and treatment. These topics are presented under the relevant subheadings, and each case covers several life areas.

\section{Understanding Own Substance Use}

Almost all the informants started the conversation talking about substance use after discharge from inpatient treatment in Tyrili. Except for one informant, all the informants had used substances after they left inpatient treatment. Some of them had used substances for a couple of days, and others had more extended periods of use.

Jesper, 37, had been in long-term inpatient treatment four times before his stay in Tyrili. He decided to quit using substances before entry into treatment. After discharge, he had two relapses but stopped again after a couple of days. The second time, his substance use was harder to control. During a demanding life period for him and his partner, he felt depressed and lonely. He explained the relapse as a result of depression and the use of alcohol, which he did not initially consider to be a relapse. After that episode, he decided to stop drinking alcohol:

I never had an alcohol problem, and I used to drink now and then, but after I quit drinking, I understood that the substance use problem was maintained when I drank. I don't think the brain separates between substances .. . Not that alcohol used to be a problem, but ... my stance on substance use and the craving became different when I drank.

The informants who had periods of severe use of substances all talked about demanding situations relating to work, troubled relationships, mental health problems, or loneliness. These struggles concerned being caught up by adverse childhood experiences, situations that arose during severe substance use, or life challenges during the years after they left treatment. They used substances as a way of coping with these struggles in life.
Jane, 31, had both an apartment and a job when she left treatment in Tyrili, and she was referred to the local psychiatric clinic for further outpatient treatment. She felt optimistic at that time:

I had a job, a house, and I started trauma treatment. It was too much for me. Working, treatment, and then going home, sitting there all by myself with my head-it was too much... I started to drink alcohol and smoke pot, and I met a crazy, mean man who beat me up and trashed my apartment... Now I have been without drugs for a couple of months. I have a nice, caring boyfriend and a job, and I feel a lot better.

Sara, 30, had significantly struggled during her life. Periodically, she used heroin for a couple of days, then stopped for one or two weeks. She reflected this about her substance use:

I hope that one day I will be able to cope without substances. However, maybe I will never just quit and stay without substances for the rest of my life, as others do. People travel on different roads.

These informants experienced several demanding challenges after inpatient treatment. They talked about the use of substances as isolated incidents or a more regular occurrence. Each described what caused the substance use and how they understood it.

\section{Feeling Safe}

The feeling of safety was closely related to violent relationships, housing, the neighbourhood or finances. Some informants had experiences of dire housing conditions and a partner who also used substances and was violent. Some lived in apartments provided by social services, while others owned their houses.

Line, 39, lived in an apartment provided by social services in a turbulent neighbourhood. She lived there for almost two years after she left treatment in Tyrili. At that time, she used substances for periods of three to four months in between short inpatient stays in SUD treatment. For her, this apartment was associated with substance use, violence and police raids:

Social services kicked me out of the apartment because of problems with people, police raids, and so on. I used a lot of amphetamine and GHB 
in that apartment, and I had a violent boyfriend. That apartment represented such bad memories... I had no place to stay for two months before they provided me with a new apartment. I feel safe here. I finally have a home for my children to visit. That means a lot to me!

When it came to personal finances, a couple of the informants had full-time paid jobs, but most received government benefits. Those who lived on low incomes struggled greatly to make ends meet, and some had relatively high monthly debts to settle:

John, 38, said this about his situation:

It is probably the best it can be. I receive a $100 \%$ disability benefit and some additional economic support. I was lucky to negotiate a debt settlement, and in two years, I had no more debt. That helps me stay away from criminality and drugs.

As described by the informants, protection from violence, safe housing and a predictable income are crucial elements in the recovery process.

\section{Understanding the Impact of Close Relationships}

The informants expressed strong emotions when talking about the close relationships in their lives. They stated that family, partners, and friends are 'for better or worse'. They either spoke about their parents as 'betrayers' and 'bastards' or as loving and supportive people. Siblings, grandparents, aunts, and uncles often represented stability and safety in families with parental SUD or mental health problems.

Jonas, 29, grew up with a mother who had an alcohol problem. His father abandoned the family and left Jonas and his siblings alone with their mother. Jonas talked about his father with both anger and grief. His mother quit drinking alcohol, and they are close now:

Today, I have close contact with my mum, sister, brother, and grandparents. Grandpa-he is in hospital, so that is hard for me. He was my best support and the only male role model when I grew up. I have given up on my father.

John, 38, talked about his relationships with his parents and siblings:

I am afraid of overdosing. I do not want my parents to wake up in the night and discover that their son is dead. If I am ok, they are ok, and I want them to feel safe and ok.

Those who had stable partners emphasised these relationships as crucial in the recovery process. Some said that their partners helped them to maintain their boundaries against substance use. As Anders, 34, said:

I started to inject again... and my partner was aware of my substance use, but as long as I went to work and ate and ... Then, when she realised that I injected, she gave me a choice to stop either using or to throw away our life together. That made me quit all by myself.

Several of the informants had children, and some male informants lived with their own and their partner's children. The women often had children living in foster homes or with their fathers. They all expressed love and care for their children and emphasised the importance of their children as a motivational factor for staying sober.

Jesper, 37, had two episodes of using drugs after leaving treatment:

We have children, and my use of substances is not compatible with raising children or anything else.

Line, 39, remarked that her struggle to stay away from substances was motivated entirely by contact with her children:

Finally, I have a nice home for my children to visit. I am sober, and the children's father and child protection services trust me enough to let them sleep over. That means a lot to me. I stay sober for them.

Family was important, and so were friends. Some informants moved to new locations after treatment, and others moved back to their hometowns. However, they all struggled to establish new friendships with people who had no substance use problems. Line, 39, said:

I have friends, but most of them use drugs. So I try to find new friends.

Lisa, 45, moved to a new city to receive outpatient treatment and continued living there. She felt that the consequences of the coronavirus pandemic hit her hard: 
The problem is that I have no friends here. Due to coronavirus, all the places I could go to meet sober people are closed down. It is easy to connect with the wrong people.

As shown, although the informants' families, partners, and friends could cause trauma and trouble, they were nevertheless crucial to recovery and fostered feelings of love and belonging.

\section{Perceptions of Participation and Belonging}

The informants emphasised the importance of having something meaningful to do during the day. This helped them stay sober and maintain contact with other people, making them feel normal and part of society.

Jane, 31, had a social worker who told her that, after she stopped using substances, she would connect her with an employer. Jane tried to communicate that having a job first would help her stop using substances:

I tried to explain to her... I just wanted a job first because that would help me to become sober. If you have a job, you have food on the table. You pay your bills, you have daily routines-ah, so few people understand this!

Jesper, 37, went to an NGO centre for people who had recently left prison or treatment after he left the SUD treatment:

It was all about coming one step further through activity. It was not so much talking as doing things together, like football or climbing or going to a concert. I was social and normal with safe people around me.

Sara, 30, went through a period when she used substances frequently, but she had found some activities that helped her stay sober:

I joined yoga classes and support groups for people with SUD. I do not use substances the day before or the same day, and I don't feel like using the day after ... so this helps me a lot.

Anne, 29, was satisfied with her life:

I feel fine. I am satisfied with my life. I work in a kitchen, I have finished my exams, and soon I will have finished my training as a chef... My self-esteem increases when I master things. In the future, I want a family, a job, and a good life.

Peter, 42, had not used any substances since he left treatment:

I have a good life. I am working and I have a family - children. I lead the board in the housing cooperative where we live; I have a responsible position at work. Things are fine... You know, having such a nice place to work and a partner... that was crucial for me ... I feel normal.

As indicated in the excerpts, doing something meaningful during the day was essential for helping the informants to stay sober. In particular, it was described as crucial for increasing the feeling of normality and participation. The informants talked about several sorts of activities, and they had found the levels and durations that suited them. Social services or volunteers organised the activities, and some participants had ordinary paid jobs.

\section{Recognise One's Needs for Support and Treatment}

All the informants received some degree of therapy and support from social services or specialised healthcare facilities during the years after inpatient SUD treatment in Tyrili. Three received opioid maintenance therapy (OMT) and were in contact with a GP or therapist. Eight had been in treatment for trauma, anxiety, depression, psychosis or insomnia, and three had or were waiting for treatment for ADHD. All had received support with housing, employment or finances. Also, four informants mentioned participation in activities and support groups run by NGOs, as described above. Five informants had received inpatient treatment for substance use and mental health problems or detox several times since they left Tyrili.

Mari, 31, started her OMT after she left Tyrili. At first, she resisted, but after becoming epileptic when using substances, her GP strongly recommended the treatment:

When I started using methadone, I regained the spark of life. I started exercising, and in a way, I got a new life.

Lisa, 45, felt lonely and depressed, living alone. She used substances frequently but was not motivated to engage with new inpatient treatment. She was 
provided with accommodation in a halfway house a couple of months before the interview:

We have our own rooms. Staff are present 24/7, and we have meals together and social contact with people in the same situation. We are all people who have been in treatment, struggled with substances, perhaps been away from work for a long time, had challenges with family, and so on. I don't feel alone here. I manage to focus on what I have, not on the things I do not have in my life.

Inpatient SUD treatment was only one step in the recovery process for these informants. They needed support and treatment thereafter-some for short periods and others potentially for the rest of their lives.

\section{Discussion}

The findings indicated that recovery processes are hard work, and feelings of wellbeing and success vary over time. During the analysis, it became clear that several interrelated aspects of life were essential in searching for a better life. Each of the informants shared their experiences and reflections about vulnerability, resources and the need for professional and social support. All except one informant had experiences of using substances after they left inpatient treatment in Tyrili. They created meaning related to substance use by referring to struggles in everyday life and powerful patterns due to former substance use. During the four years after they left inpatient treatment in Tyrili, they emphasised that feeling safe when it came to housing, the neighbourhood, violence or finances was essential. Close relationships with their families, partners, and friends were both demanding and helpful and elicited strong emotions. Participation in meaningful activities was necessary for the informants' feelings of normality. The activities varied from ordinary jobs and work training to activities like yoga and self-help groups for people with mental health and substance use problems. All the informants had received professional support or therapy after they left inpatient SUD treatment, including economic support, work training, housing, trauma therapy, detox or inpatient treatment. They underlined the importance of having access to such treatment and support because it helped them to cope with difficult emotions, thoughts and life situations without using substances, or it provided support to stop using substances after relapses.

\section{A Comprehensive Understanding of SUD and Recovery}

The findings revealed a variety of areas that are important for understanding SUD and the recovery process. Each of the informants' searches for a better life was unique, but they also shared many experiences. There has been a tradition of understanding SUD primarily as a biological disease to be treated with medicine [8], as a psychological issue caused by traumas, relational problems or a lack of secure attachment, requiring therapy [14, 18], or as a social and cultural problem caused by inadequate living conditions, poverty and a lack of social and psychological support [1]. In line with other studies, our findings indicated the importance of understanding the complexity of SUD and acknowledging individual perspectives [2, 15, 37]. Listening to the informants “ stories about adverse life situations and struggles may increase professionals' understanding of SUD as a multifactorial problem. This understanding of SUD, employing a biopsychosocial approach, may, in turn, contribute to lessening the stigma and shame associated with SUD [23, 45]. Individual perceptions of wellbeing and quality of life varied considerably among the informants. Peter, 42, was sober, had his own house, a partner, children, and a job. He emphasised feelings of normality and coping in life. Sara, 30, by contrast, was not motivated to stop using substances, and she was satisfied by participating in yoga classes and support groups for people with substance use problems. As a result, the recovery process should also be understood as personal and multifactorial [21, 32].

It has been criticized that treatment and the ongoing recovery process focuses on substance use only [6]. Substance use was influential in informants' narratives but closely connected to other areas of life, such as mental health, close relationships, safe housing and meaningful daytime occupations. Also, the biological and psychological impacts of using substances, as well as individual reflections on either quitting all substances or maintaining the use of alcohol or marihuana, were essential parts of the informants' meaning-making. This suggests that professionals 
should not take for granted that a total absence of substances is 'everybody's aim and should not necessarily define periodic or sporadic substance use as failure [2, 6, 30, 39]. Personal, relational, and environmental resources are often referred to as recovery capital, which contributes to improving wellbeing and the control of substance use [17, 30]. Safe housing, close relationships, and activities were essential for the informants to reach their goals of controlling or quitting substance use. The absence of such resources could contribute to relapses. In particular, family, partners, and friends were mentioned as both resources and as people who caused trouble and pain. This is in line with former research on recovery, which emphasised the importance of social relationships during a recovery-process [22, 31, 35, 43, 44].

\section{Interdisciplinary Professional Support}

Recovery is not a linear process. For many people, the process includes stable periods and periods characterised by emotional, relational, and social pain and trouble [6]. Thus, recovery processes should be met with patience and adjusted and collaborative support. All the informants had received professional support and interventions following discharge from inpatient treatment in Tyrili, including mental health care in periods when substance use was a minor problem. We interpreted the informants' statements to mean that they did not see this as a defeat. They acknowledged that they needed help and support. Due to these findings, we suggest that one inpatient treatment stay is often inadequate for reaching personal wellbeing and a higher quality of life. Being in recovery includes a long-time search for a better life and increased quality of life with the collaborative support of others, including professionals, when needed $[6,15,21,27,28]$.

A critical message from informants was that the shutdown during the coronavirus pandemic increased feelings of abandonment and loneliness, as demanding periods in society often strike the most vulnerable inhabitants hardest $[4,46]$.

\section{Conclusion}

SUD and recovery should be understood using the same coherent approach-as an interplay between biological and psychological factors and social, political and cultural contexts. This study emphasised that inpatient treatment is necessary but inadequate for many people with SUD, and long-time access to various professional and social support systems is crucial in the recovery process. Receiving such support is not understood as a defeat, and each person's resources and vulnerabilities should be recognized and acknowledged.

Funding This study and all authors have received no funding.

\section{Declaration}

Conflict of interest There is no conflict of interest.

\section{References}

1. Adrian M. How can sociological theory help our understanding of addictions? Subst Use Misuse. 2003;38(10):1385-423.

2. Alves P, Sales C, Ashworth M. Does outcome measurement of treatment for substance use disorder reflect the personal concerns of patients? A scoping review of measures recommended in Europe. Drug Alcohol Depend. 2017; 179:299.

3. Benton T, Craib I. Philosophy of social science: the philosophical foundations of social thought. 2nd ed. London: Palgrave Macmillan; 2011.

4. Benzano D, Ornell F, Schuch JB, Pechansky F, Sordi AO, von Diemen L, Kessler FHP. Clinical vulnerability for severity and mortality by COVID-19 among users of alcohol and other substances. Psychiatry Res. 2021;300:113915-113915. https://doi.org/10.1016/j. psychres.2021.113915.

5. Bergly T, Sømhovd M. The relation between ADHD medication and mild cognitive impairment, as Assessed by the Montreal Cognitive Assessment (MoCA), in patients entering substance use disorder inpatient treatment. J Dual Diag. 2018;14(4):228-36. https://doi.org/10.1080/ 15504263.2018.1496305.

6. Bjornestad J, McKay JR, Berg H, Moltu C, Nesvåg S. How often are outcomes other than change in substance use measured? A systematic review of outcome measures in contemporary randomised controlled trials. Drug Alcohol Rev. 2020;39(4):394-414. https://doi.org/10.1111/dar. 13051.

7. Bjørlykhaug KI, Karlsson B, Hesook SK, Kleppe LC. Social support and recovery from mental health problems: a scoping review. Nordic Social Work Research. 2021. https://doi.org/10.1080/2156857X.2020.1868553

8. Blume AW, Rudisill DM, Hendricks S, Santoya N. Disease Model. In: Miller PM, editor. Principles of Addiction. Elsevier Science \& Technology; 2013. p. 71-6.

9. Brekke E, Lien L, Biong S. Experiences of professional helping relations by persons with co-occurring mental 
health and substance use disorders. Int $\mathrm{J}$ Ment Health Addict. 2017;16(1):53-65. https://doi.org/10.1007/s11469017-9780-9.

10. Duncan PM. Substance Use Disorders. A Biopsychosocial Perspective. Cambridge: Cambridge University Press; 2020.

11. Engel G. The need for a new medical model: a challenge for biomedicine. Psychodynamic Psychiatry. 1977;40(3):377-96.

12. Farrell A. Ethical research with children. New York: McGraw-Hill Education; 2007.

13. Gergen KJ. An invitation to social construction. 3rd ed. New York: SAGE; 2015.

14. Gil-Rivas V, McWhorter L. Self-Medication. In: Miller PM, editor. Principles of Addiction: Coprehensive Behaviors and Diseases. Amsterdam: Elsevier Science and Technology; 2013. vol. 1, p. 236-40.

15. Gillard S, Turner K, Neffgen M. Understanding recovery in the context of lived experience of personality disorders: a collaborative, qualitative research study. BMC Psychiatry. 2015;15(1):183. https://doi.org/10.1186/s12888-015-05720.

16. Goffman E. Stigma: notes on the management of spoiled identity. New York: Penguin; 1968.

17. Hennessy EA. Recovery capital: a systematic review of the literature. Addiction Research \& Theory. 2017;25(5):349-60. https://doi.org/10.1080/16066359. 2017.1297990.

18. Hunter-Reel D. Interpersonal Factors and Addictive Disorders. In: Miller PM, editor. Principles of Addiction: Coprehensive Behaviors and Diseases. Amsterdam: Elsevier Science and Technology; 2013. vol. 1, p. 292-301.

19. Kassel JD, Veilleux JC, Heinz AJ, Braun AR, Conrad M. Emotions and Addictive Processes. In: Miller PM, editor. Principles of Addiction: Comprehensive Addictive Behaviors and Disorders. Amsterdam: Elsevier Science \& Technology; 2013. p. 213-22.

20. Kvale S, Brinkmann S. Interviews: learning the craft of qualitative research interviewing. 2nd ed. London: Sage; 2009.

21. Laudet ABPD, White WMA. What are your priorities right now? Identifying service needs across recovery stages to inform service development. $J$ Subst Abuse Treat. 2010;38(1):51-9. https://doi.org/10.1016/j.jsat.2009.06. 003.

22. Leamy M, Bird V, Le Boutillier C, Williams J, Slade M. $12 / 01)$. Conceptual framework for personal recovery in mental health: Systematic review and narrative synthesis. Br J Psych J Mental Sci. 2011;199:445-52. https://doi.org/ 10.1192/bjp.bp.110.083733.

23. Livingston JD, Milne T, Fang ML, Amari E. The effectiveness of interventions for reducing stigma related to substance use disorders: a systematic review. Addiction. 2012;107(1):39-50. https://doi.org/10.1111/j.1360-0443. 2011.03601.x.

24. Magnusson E, Marecek J. Doing interview-based qualitative research: A learner's guide. Cambrigde: Cambrigde University Press; 2015.

25. Miller PM. Principles of Addiction: Comprehensive Addictive Behaviors and Disorders. San Diego: Elsevier Science \& Technology; 2013.
26. Neale J, Tompkins C, Wheeler C, Finch E, Marsden J, Mitcheson L, Rose D, Wykes T, Strang J. You're all going to hate the word "recovery" by the end of this: Service users' views of measuring addiction recovery. Drugs Educ Prev Policy. 2015;22(1):26-34. https://doi.org/10.3109/ 09687637.2014 .947564$.

27. Neale J, Vitoratou S, Finch E, Lennon P, Mitcheson L, Panebianco D, Rose D, Strang J, Wykes T, Marsden J. Development and validation of 'sure': a patient reported outcome measure (prom) for recovery from drug and alcohol dependence. Drug Alcohol Depend. 2016;165:159-67. https://doi.org/10.1016/j.drugalcdep.2016.06.006.

28. Ness O, Borg M, Semb R, Karlsson B. "Walking alongside:" collaborative practices in mental health and substance use care. Int J Ment Health Syst. 2014;8(1):55-55. https://doi.org/10.1186/1752-4458-8-55.

29. Noordsy DL, Mishra MK, Mueser KT. Models of relationships between substance use and mental disorders. In: Miller PM, editor. Principles of Addiction: Coprehensive Behaviors and Diseases. San Diego: Elsevier Science \& Technology; 2013. vol. 1, p. 489-94.

30. O'Sullivan D, Xiao Y, Watts JR. Recovery capital and quality of life in stable recovery from addiction. Rehabil Couns Bull. 2019;62(4):209-21. https://doi.org/10.1177/ 0034355217730395.

31. Pettersen H, Landheim A, Skeie I, Biong S, Brodahl M, Oute J, Davidson L. How social relationships influence substance use disorder recovery: a collaborative narrative study. Subst Abuse. 2019;13:1178221819833379. https:// doi.org/10.1177/1178221819833379.

32. Roll JM. Contextual Factors in Addiction. In: Miller PM, editor. Principles of Addiction Comprehensive Addictive Behaviors and Disorders. San Diego: Elsevier Science \& Technology; 2013. vol. 1, p. 243-8.

33. Ross D, Kincaid H, Spurrett D, Collins D. What Is Addiction? United States: Mit Press; 2010. https://doi.org/10. 7551/mitpress/9780262513111.001.0001.

34. Schumm JA, O`Farrell, T. J. . Families and Addiction. In: Miller PM, editor. Principles of Addiction: Comprehensive Addictive Behaviors and Disorders. San Diego: Elsevier Science \& Technology; 2013. vol. 1, p. 303-12.

35. Selbekk AS, Adams PJ, Sagvaag H. A problem like this is not owned by an individual: Affected family members negotiating positions in alcohol and other drug treatment. Contemp Drug Prob. 2018. https://doi.org/10.1177/ 0091450918773097.

36. Silverman D. Interpreting qualitative data. 5th ed. London: SAGE; 2014.

37. Skewes MC, Gonzalez VM. The Biopsychosocial Model of Addiction. In: Miller PM, editor. Principles of Addiction: Comprehensive Addictive Behaviors and Disorders. San Diego: Elsevier Science and Technology; 2013. vol. 1, p. 61-70.

38. Slade M, Oades LG, Jarden A. Wellbeing, recovery and mental health. Cambrigde: Cambridge University Press; 2017.

39. Steckler G, Witkiewitz K, Marlatt GA. Relapse and Lapse. In: Miller PM, editor. Principles of Addiction: Coprehensive Behaviors and Diseases. San Diego: Elsevier Science \& Technology; 2013. vol. 1, p. 126-31. 
40. Sømhovd M, Hagen E, Bergly T, Arnevik EA. The Montreal Cognitive Assessment as a predictor of dropout from residential substance use disorder treatment. Heliyon. 2019;5(3):e01282-e01282. https://doi.org/10.1016/j. heliyon.2019.e01282.

41. Tew J, Ramon S, Slade M, Bird V, Melton J, Le Boutillier C. Social factors and recovery from mental health difficulties: a review of the evidence. $\mathrm{Br} \mathrm{J}$ Social Work. 2011;42(3):443-60. https://doi.org/10.1093/bjsw/bcr076.

42. Toneatto T. Natural Recovery. In: Miller PM, editor. Principles of Addiction: Coprehensive Behaviors and Diseases. San Diego: Elsevier Science \& Technology; 2013. vol. 1, p. $133-8$.

43. Topor A, Borg M, Di Girolamo S, Davidson L. Not just an individual journey: social aspects of recovery. Int J Soc Psychiatry. 2009;57(1):90-9. https://doi.org/10.1177/ 0020764009345062.

44. Veseth M, Moltu C, Svendsen TS, Nesvåg S, Slyngstad TE, Skaalevik AW, Bjornestad J. A stabilizing and destabilizing social world: close relationships and recovery processes in SUD. J Psychosoc Rehabilit Ment Health. 2019;6(1):93-106. https://doi.org/10.1007/s40737-01900137-9.
45. Wangensteen T, Halsa A, Bramness JG. Creating meaning to substance use problems: a qualitative study with patients in treatment and their children. J Subst Use. 2020;25:1-5. https://doi.org/10.1080/14659891.2020.1715497.

46. Welle-Strand GK, Skurtveit S, Clausen T, Sundal C, Gjersing L. COVID-19 survey among people who use drugs in three cities in Norway. Drug Alcohol Depend. 2020;217:108302. https://doi.org/10.1016/j.drugalcdep. 2020.108302 .

47. West R, Brown J. Theory of Addiction. 2nd ed. New York: Wiley; 2013.

48. Wiechelt SA. The Specter of Shame in Substance Misuse. Subst Use Misuse. 2007;42(2-3):399-409. https://doi.org/ $10.1080 / 10826080601142196$.

49. Young RM. Craving and Expectancies. In: Miller PM, editor. Principles of Addiction: Coprehensive Behaviors and Diseases. San Diego: Elsevier Science and Technology; 2013. vol. 1, p. 425-33.

Publisher's Note Springer Nature remains neutral with regard to jurisdictional claims in published maps and institutional affiliations. 